\title{
Nothing Ventured - Nothing Gained? Empirical Evidence on Venture Capital Financing in Switzerland
}

\author{
Christian Hopp
}

JEL-Classification: G24, G31

Keywords: Venture Capital, Entrepreneurship, Syndication

\section{Introduction}

In addition to the various studies on Venture Capital financing in the US, recent empirical research has analysed the markets for Private Equity and Venture Capital (VC) in several established European countries. The emerging literature refrains from transferring findings from the US VC industry one-to-one to Europe and pays growing attention to the individual characteristics of $\mathrm{VC}$ markets in different regions (JENG and Wells, 2000). Nevertheless, the evidence on less developed markets with a blossoming need for growth capital has largely been neglected. The lack of additional comprehensive studies analyzing the investment behavior of Venture Capitalists (VCs) in smaller markets calls for further research in this field. As MANigART et al. (2002) point out there is a wide range of economic, legal, institutional and cultural differences influencing the environment in which VCs operate. Thus, the miscellaneous and comprehensive conclusions drawn on the North American VC market are not necessarily applicable to the European VC industry as a whole. This paper aims at filling this gap by investigating the behavior of VCs in Switzerland with respect to financing mechanisms employed and the extent to which collaboration between VCs is used to cope with informational barriers. It is the first of its kind to explicitly focus on

* Thurgau Institute of Economics at the University of Konstanz, Box D 147, D-78457, Konstanz, Germany. Christian.Hopp@uni-konstanz.de, and Institut für Finanzdienstleistungen Zug (HSW Luzern). This research has been carried out as a joint initiative between the Thurgau Institute of Economics and the IFZ, Zug. I would like to thank Maurice Pedergnana for the supervision of this project, Nicolas Bürkler for his research assistance, and an anonymous referee and Klaus Neusser (the editor) for helpful comments. 
the Swiss market and adds to the growing empirical literature on staging and syndication in European countries.

Concerning the role of VCs, one can presume that the use of a staged financial structure can be as important as the pure provision of capital. Overcoming the problem of asymmetric information and monitoring the activities of portfolio firms can be valuable. Thus, I analyze to which extent VCs investing in Switzerland make use of staged capital infusions. I start by documenting the driving forces of staging for VCs operating in Switzerland. I find that among the different affiliations of VC investors in Switzerland especially independent investors make more extensive use of stage financing. Moreover, the results suggest that staging is employed as a tool for mitigating risks. Firms that focus more extensively on certain stages employ on average more financing rounds.

Recent literature has shown that firms can join forces with other partners to combine resources and capabilities in order to overcome information asymmetries and gain access to deal flow. I investigate the reasons behind the formation of such syndicates and estimate the effect that cooperation of financial institutions has on the value and prospects of the funded portfolio company. I find that foreign investors make more extensive use of syndication efforts when investing in the Swiss market. Syndication allows the foreign investors to spread their capital over a larger number of deals without diluting effort available to the other funded firms. Moreover, syndication can serve as an entrance strategy to new markets. In addition, I find that VCs which use staged capital infusions are more prone to join forces with partners. This is in line with the argumentation of FluCK, Garrison and Myers (2005) suggesting that the syndication of VC investments could alleviate agency problems between the $\mathrm{VC}$ and the entrepreneur and consequently, VCs that make use of staging should also be more open to syndication.

Concerning the value added effect of syndication and staging activities I find that Swiss VCs seem to have problems either in exiting their deals, or might even exhibit difficulties in providing the necessary value added in managing their investments. Overall VCs that are more locally embedded (as measured by a locality dummy) do exhibit lower success rates for their investment portfolio. Moreover, I show that syndication positively impacts the success rate of VCs providing evidence on a value added effect of VC Syndication.

The remainder of the paper is organized as follows. In Chapter 2 I will summarize the related literature. Chapter 3 introduces the data set used in this paper. In Chapter 4 I will discuss the factors impacting the staging and monitoring of $\mathrm{VC}$ investments and present and discuss the implications of the regression results. Chapter 5 concludes. 


\section{Related Literature}

There is widespread evidence on the financing behavior of VCs in established markets. SAHLMAN (1990) points out that when the investment is staged and the capital infusions take place in smaller increments, rather than involving a large upfront payment, the prospects of the firm are re-evaluated on an ongoing basis. FLUCK et al. (2005) point out that staged financing benefits VCs in two ways. First of all, it can block the entrepreneur's incentive to continue investing in bad projects to generate private benefits and allows the VCs to exploit the venture's real option value by being able to stop investing once the venture turns out to be less successful than expected. WANG and ZHOU (2002) also argue that staging reduces the cost associated with bad information (the real option value of abandonment) and decreases the agency costs of moral hazard. As such, staging can solve different purposes in early and later rounds.

The two commonly employed mechanisms of staged financing are milestones, where the financed firm receives a new capital injection contingent upon certain criteria being met, and round financing where no explicit commitment for an additional round of financing is made. TALMOR and CUNY (2005) analyze various factors impacting the choice between round financing and milestones. They find that if the role of the venture capitalist is more important than the entrepreneur, milestone financing is more efficient than round financing and vice versa. BIENZ and Hirsch (2005) analyze the role of milestones versus round financing in the context of German VC agreements. In round financing each new capital infusion is negotiated separately, whereas in milestone financing the decision whether to inject new capital is made contingent on the portfolio company meeting predefined targets in terms of product development or financial figures. BIENZ and Hirsch arrive at the conclusion that the decision to stage is determined by the inherent uncertainty and the degree of asymmetric information. The form of staging, however, is determined by the predictability of the development process and the anticipated bargaining power of the involved parties.

The role played by VCs in the financing process goes beyond the mere provision of money. BRANDER et al. (2005) point out the value adding effect of syndication activities and Audretsch and Lehmann (2004) empirically show that the syndication of investments can lead to higher sales growth. Recent studies argue that there are two main motives that complement each other when explaining why $\mathrm{VCs}$ choose to co-invest with a partner: the risk-mitigating perspective and the resource-based perspective [Hopp and RIEDER, 2006; BRANDER et al., 2002; Manigart et al., 2005). The Risk Mitigating Perspective sees syndication as a mean for VCs to build up a well-diversified portfolio and reduce 
risk without reducing return, while the resource-based approach, sees the VC market as a pool of productive resources in which VCs can access resources of partners through syndication (Manigart et al., 2005; Bygrave, 1987). FluCK et al. (2005) present a model of VC contracting that incorporates moral hazard, and asymmetric information problems. They show that later stage syndication of VC investments alleviates the agency problems between the VCs and the entrepreneurs. Syndication reduces the monopoly power of the financing firm and thus induces the entrepreneur to put in more effort. FLUCK et al. point out that the commitment to syndicate can protect the entrepreneur from dilution and thus mitigates the problem of hold-up. The commitment to syndicate therefore assures a higher effort of the entrepreneur and yields more favorable financing terms in return.

\section{The Data}

In order to make inferences on the staging and syndication behavior I make use of a data set on VC transactions in Switzerland. The sample consists of $423 \mathrm{VC}$ transactions in Switzerland within the period 1989-2005, whereas the majority of the deals undertaken is concentrated in the later years. The transactions have been compiled by using public sources and the Thomson Venture Economics (TVE) Database. I have identified the involved parties in each transaction and the corresponding information on the $\mathrm{VC}$ along with the funded firms. The result is a deal survey exhibiting who has funded a new company and was joined by which partner. Moreover, I collected information about each financing round. Hence, I can identify which VCs have made investments into a target firm at which point in time.

In order to give an idea about the distribution of investments over time and industries I used the information from TVE to identify the sector of a particular venture. Here I make use of the Venture Economics Industry Classification (VEIC) - a Venture Economics proprietary industry classification scheme. I divided the Medical/Health classification in two separate categories. I created categories for Software and Internet firms to illustrate the importance of investments into "New Economy" firms over the period. In addition, I collected information about the different stages of development when an investment has been made. TVE gives information about five different categories: Start Up/Seed, Early Stage, Expansion, Later Stage and Other. Similar to Gompers (1995) who labels the categories for bridge, second and third stage financing as "Late Stage" financing, I combined the TVE categories Expansion, Later Stage and Other to 
form a new category, that I also label "Late Stage". As there is no clear distinction between Expansion financing, that almost always occur in later phases, and other financing activities, that namely concern bridge financing or special purpose financing, from the "Later Stage" category this combination appears to be the most reasonable classification scheme.

Table 1 shows that the number of transactions increased until the year 2001 with a peak of 99 VC deals. The years 2002-2004 have seen a steady level of investment activity of 30 transactions. With respect to the industries financed one can see that Internet firms have been attractive during the dot.com boom but have not been of interest to VCs ever since. The same effect can be found for Software firms that peaked during the years 1999 and 2000 and steadily declined to $6,5 \%$ of the total transactions undertaken in 2004 (from about 30\% in 1999 and $24 \%$ in 2000). The relative importance of Biotech, Medical and Pharmaceutical firms has experienced a constant interest from the side of the VCs over the late 90s and the importance has even increased with the ending of the dot. com boom in 1999/2000. The number of deals in the "Old Economy" industries such as Industrial Products and Electronics has plunged in the late 90s but has gained significance over the recent years.

Table 1 also provides evidence about the distribution of financing events across stages of development. One can infer that the focus of the VCs has been more on Later Stage financing until the year 1999. Start Up and Seed financing remained on a relatively modest level and only gained significance with the beginning of the new millennium. This also emphasizes the relatively juvenile market in Switzerland, where the initial investment steps concentrated on less risky late stage transactions. With the growing experience gained through investing, VCs shifted their focus to earlier stages of the investment life cycle. In the later years the investments have been made roughly equally in all stages of development.

For the scope of the upcoming analysis I included the characteristics of the VCs to see how those factors impact the decision to stage an investment or make use of extensive partnering. I classify the companies as being an independent venture capitalist if there are no strings to other firms or banks attached. Secondly, I classify VCs as banking dependent when a private bank has founded them or a private bank holds more than $50 \%$ of the shares. Thirdly, I classify VCs as public if the shares are hold by either a government or by a governmental public fund. Additionally, I included corporate VCs when the fund has strings to a large corporation. In order to control for locality effects I included a dummy variable equaling one when the venture vapitalist has an office in Switzerland from which it operates and zero otherwise. This "Swiss Office" dummy is used to estimate the impact that familiarity and proximity to the local market and its particularities 
Table 1: Round Financing by Industry 1989-2005 and Stage of Development 1995-2005

\begin{tabular}{|c|c|c|c|c|c|c|c|c|c|c|c|c|c|c|c|c|c|c|}
\hline \multirow[t]{2}{*}{ Year } & 1989 & 1990 & 1992 & 1993 & 1994 & 1995 & 1996 & 1997 & 1998 & 1999 & 2000 & 2001 & 2002 & 2003 & 2004 & 2005 & \multicolumn{2}{|c|}{$1995-2005$} \\
\hline & \multicolumn{16}{|c|}{ Panel A: Percentage of Yearly Rounds by Industry } & Average & Observations \\
\hline Biotech & 0 & 0 & 0 & 0 & 0 & 0 & 20 & 60.9 & 1.61 & 24.5 & 12.1 & 14.5 & 10 & 33.3 & 12.9 & 0 & 16.3 & 69 \\
\hline Consumer & 0 & 0 & 100 & 0 & 0 & 0 & 0 & 0 & 0 & 1.9 & 0 & 1.3 & 0 & 0 & 0 & 0 & 0.7 & 3 \\
\hline Consulting & 0 & 0 & 0 & 0 & 100 & 0 & 0 & 0 & 0 & 3.7 & 6.1 & 5.3 & 0 & 0 & 3.2 & 0 & 3.3 & 14 \\
\hline Electronics & 100 & 0 & 0 & 0 & 0 & 33.3 & 40 & 0 & 1.6 & 16.9 & 9.1 & 19.7 & 20 & 30 & 0 & 66.7 & 13.5 & 57 \\
\hline Financial & 0 & 0 & 0 & 0 & 0 & 0 & 0 & 0 & 0 & 7.6 & 3 & 0 & 10 & 0 & 6.5 & 0 & 2.8 & 12 \\
\hline Internet & 0 & 0 & 0 & 0 & 0 & 0 & 0 & 4.4 & 9.7 & 5.7 & 11.1 & 2.6 & 0 & 0 & 0 & 0 & 5.4 & 23 \\
\hline Ind. Products & 0 & 0 & 0 & 0 & 0 & 0 & 0 & 26.1 & 14.5 & 3.8 & 16.2 & 2.6 & 16.7 & 6.7 & 0 & 0 & 9.9 & 42 \\
\hline Media & 0 & 0 & 0 & 0 & 0 & 66.7 & 0 & 0 & 3.2 & 1.9 & 9.1 & 7.9 & 0 & 3.3 & 9.7 & 33.3 & 5.9 & 25 \\
\hline Medical & 0 & 0 & 0 & 0 & 0 & 0 & 20 & 0 & 37.1 & 3.8 & 1 & 25 & 3.3 & 6.7 & 3.2 & 0 & 11.8 & 50 \\
\hline Software & 0 & 0 & 0 & 100 & 0 & 0 & 20 & 8.7 & 11.3 & 30.2 & 24.2 & 19.7 & 13.3 & 13.3 & 6.5 & 0 & 18.2 & 77 \\
\hline Pharma & 0 & 100 & 0 & 0 & 0 & 0 & 0 & 0 & 20.1 & 0 & 8.1 & 1.3 & 26.7 & 6.7 & 58.1 & 0 & 12.1 & 51 \\
\hline \multirow[t]{2}{*}{ Total } & 3 & 1 & 1 & 2 & 1 & 3 & 5 & 23 & 62 & 53 & 99 & 76 & 30 & 30 & 31 & 3 & & 423 \\
\hline & \multicolumn{16}{|c|}{ Panel B: Percentage of Yearly Rounds by Stage of Development } & & \\
\hline Start Up & 0 & 0 & 0 & 100 & 0 & 66.7 & 0 & 0 & 8.1 & 30.2 & 23.2 & 31.6 & 23.3 & 20 & 54.8 & 0 & 24.1 & 102 \\
\hline Early Stage & 100 & 100 & 0 & 0 & 0 & 0 & 0 & 30.4 & 29.1 & 41.5 & 19.2 & 28.9 & 13.3 & 63.3 & 6.5 & 0 & 27.6 & 117 \\
\hline Late Stage & 0 & 0 & 100 & 0 & 100 & 33.3 & 100 & 69.6 & 62.9 & 28.3 & 57.6 & 39.5 & 63.3 & 16.7 & 38.7 & 100 & 48.2 & 204 \\
\hline
\end{tabular}

The table reports the yearly distribution of 423 Financing events over the years 1989-2005. The deals have been collected until the 31st of August 2005. The Financing Rounds have been made into 176 firms by 223 VC providers across the industries indicated. Panel A shows the industry composition of the VC investments in the sample over time. Panel B shows the variations in the the stage of development for the investments in the sample. Industry classifications are based on TVE VEIC codes. Further industry splitting has been made for Medical, Pharma and Biotech. Moreover, the category Internet has been introduced to cope with "New Economy" firms. Stages include TVE indicated Start Up/Seed and Early Stage. The TVE categories "Expansion", "Later Stage" and "Other" have been grouped in the new category "Late Stage". All values are shown in percent, despite for the last row and the last column that aggregate numbers over time and industry/stage respectively. 
might have on the decision to co-invest or make use of monitoring and control mechanisms in order to overcome information asymmetries.

Table 2 reports the characteristics of the VCs in the sample. One can infer that among the firms that provided capital to young and innovative firms, independent VCs outnumber the other firms active in the Swiss market. Moreover, those firms turn out to focus more on specific industries. TVE provides information about the investment focus for the various investors in the sample. TVE distinguishes between firms that have a focus on Medical/Health and Pharmaceutical companies, Information Technology or Non-High firms. The TVE information on focus industries reveals that among independent investors, about a third of the firms focus on investments into Information Technology and roughly five percent focus on Non-High Technology and ten percent on Medical firms. Among the categories roughly a third of the VCs active in the Swiss market operate from a Swiss Office, with corporate investors being mostly from a foreign origin.

Column (7) in table 3 reports the average number of financing events by VCs from each category. Once it comes to an investment, corporate VCs have provided the largest number of rounds on average followed by independent VCs. Interestingly public VCs have on average participated only in a single financing round when an investment is made. The extent of staging therefore differs among the VC provider categories. Later on I will try to shed more light on the staging patterns that emerge and investigate what impacts the decision to stage capital infusions. For further analysis I also describe the VCs by their syndication ratio that is expressed by the ratio of syndicated investments to the total number of deals. The higher the syndication ratio of an investor, the more he tends to invest in portfolio companies that are funded through a co-investment. A syndication ratio of " 0 " indicates that the specific investor invested exclusively on his own and was not involved in any co-investment. Table 2 reveals that joint investment activity is more pronounced among corporate and public investors, whereas independent VCs exhibit a lower syndication ratio and tend to invest to a lesser extent with a partner.

Additionally I have included variables describing the VC investors further. TVE provides information about Capital under Management ("Capital”) for the VCs, along with information on the overall sum invested in Switzerland ("Sum") and the Swiss investment size as a percentage of the overall investment activity world-wide ("Percentage"). Moreover, I have included the number of funds managed totally for the VCs to proxy for size and experience beyond the pure capital available for a single fund. From table 2 one can infer that independent and banking VCs have the largest amount of Capital under Management measured in Million Euro. Moreover, independent and corporate VCs invested the largest 
Table 2: Summary Statistics for Venture Capital Providers: Aggregated Numbers for VC categories

\begin{tabular}{|c|c|c|c|c|c|c|}
\hline & 1-Total Firms & 2-Swiss Office & 3-Non-High Tech & 4-Information & 5-Medical & 6-No Focus \\
\hline Banking & 44 & 12 & 3 & 9 & 4 & 27 \\
\hline Corporate & 29 & 3 & 2 & 13 & 3 & 5 \\
\hline Independent & 148 & 45 & 9 & 58 & 19 & 65 \\
\hline \multirow[t]{2}{*}{ Public } & 12 & 4 & 1 & 2 & 1 & 7 \\
\hline & 7-Average Rounds & 8-Syndication Ratio & 9-Capital & $10-$ Sum & 11-Percentage & 12-Funds \\
\hline Banking & 1.26 & 0.84 & 1,141 & 6.04 & 0.17 & 6.57 \\
\hline Corporate & 1.43 & 0.90 & 191 & 14.2 & 0.28 & 3.26 \\
\hline Independent & 1.36 & 0.75 & 1,044 & 13.3 & 0.24 & 4.90 \\
\hline Public & 1.00 & 0.88 & 447 & 10.2 & 0.29 & 1.90 \\
\hline
\end{tabular}

The table reports the Summary Statistics for the VC providers in the sample. The data has been obtained through the use of the Thomson Venture Economics Database and public sources for identifying transactions and the involved parties. Column (1) gives information about the Total firms belonging to each category. Column (2) reports how many firms within the group have at least one Swiss Office from which it operates. Additionally, columns (3) till (6) give information about the number of VC firms from each category that have an investment focus as indicated by TVE in Non-High Tech firms, Information Technology firms or Medical and Life Science firms respectively, or no specified investment Focus at all. Column (7) provides information about the Average Number of Financing Rounds per investment undertaken. Column (8) contains information about the Syndication Ratio for each VC category. The Syndication Ratio measures to which extent VC firms make use of joint investment actions and is calculated as the ratio of syndicated investments to the number of total transactions by the respective VC. Column (9) presents the Capital under Management for the VC categories and is measured in Mio. Euro. Column (10) gives the sum of total investments made in Switzerland as indicated by TVE and is measured in Mio. Euro. Column (11) indicates which percentage of overall investment volume has been undertaken in Switzerland. Column (12) indicates the average number of Funds managed by a VC group as indicated by TVE. 
amount of capital in Switzerland, and also invested (along with public investors) the largest chunk of their funds into the Swiss market. In terms of funds managed independent and banking investors show the highest investment activity with an average of some 5 and 3 funds managed, respectively.

\section{The Financing and Co-Investment Behavior of Venture Capital Providers in Switzerland}

\subsection{VC Characteristics and the Need for Staging and Monitoring}

In order to test which VCs are more likely to invest in stages I estimate an OLS regression with the $\mathrm{VC}$ provider characteristics as the explanatory variables and the average number of financing rounds per $\mathrm{VC}$ provider as the dependent variable. The explanatory variables include the VC categories introduced in chapter 2 (i.e. Independent, Banking, etc.), a variable indicating the focus of the VCs (i.e. whether the firm concentrates their investments into Non-High Tech firms, Information Technology firms, or Medical firms). In order to control for locality effects I include a dummy variable equaling one if the VC operates from a Swiss Office and zero otherwise. Gompers (1995) has pointed out that problems of asymmetric information become more pronounced with less proximity between the VCs and the investment target. It might be interesting to see how these factors impact the extent of staging activities. In addition, I included variables indicating the Capital under Management, the size of previous deals done in Switzerland, the number of funds managed and the volume of total transactions done in Switzerland as a percentage of the worldwide volume of transactions. Moreover, I calculated the concentration on certain stages as well as the concentration on industries for the VCs to see how the portfolio influences the need for staging. Therefore the closer the index is to one, the more the deals are concentrated within a few industries (stages). The total number of investments undertaken by the VCs is also included into the regression to test for the influence of size and experience on the use of staged financing.

The results are reported in table 3 . One can infer that among the VC categories only the coefficient associated with the dummy variable for independent $\mathrm{VC}$ investors is positive and significant among five regression specifications (at least at the 5\% level) indicating that in comparison with public investors (as this dummy has been omitted from the regression to avoid perfect collinearity) independent investors make more extensive use of stage financing. The coefficients associated with the other dummy variables are not significant at conventional 
Table 3: VC Characteristics and Average Number of Financing Rounds

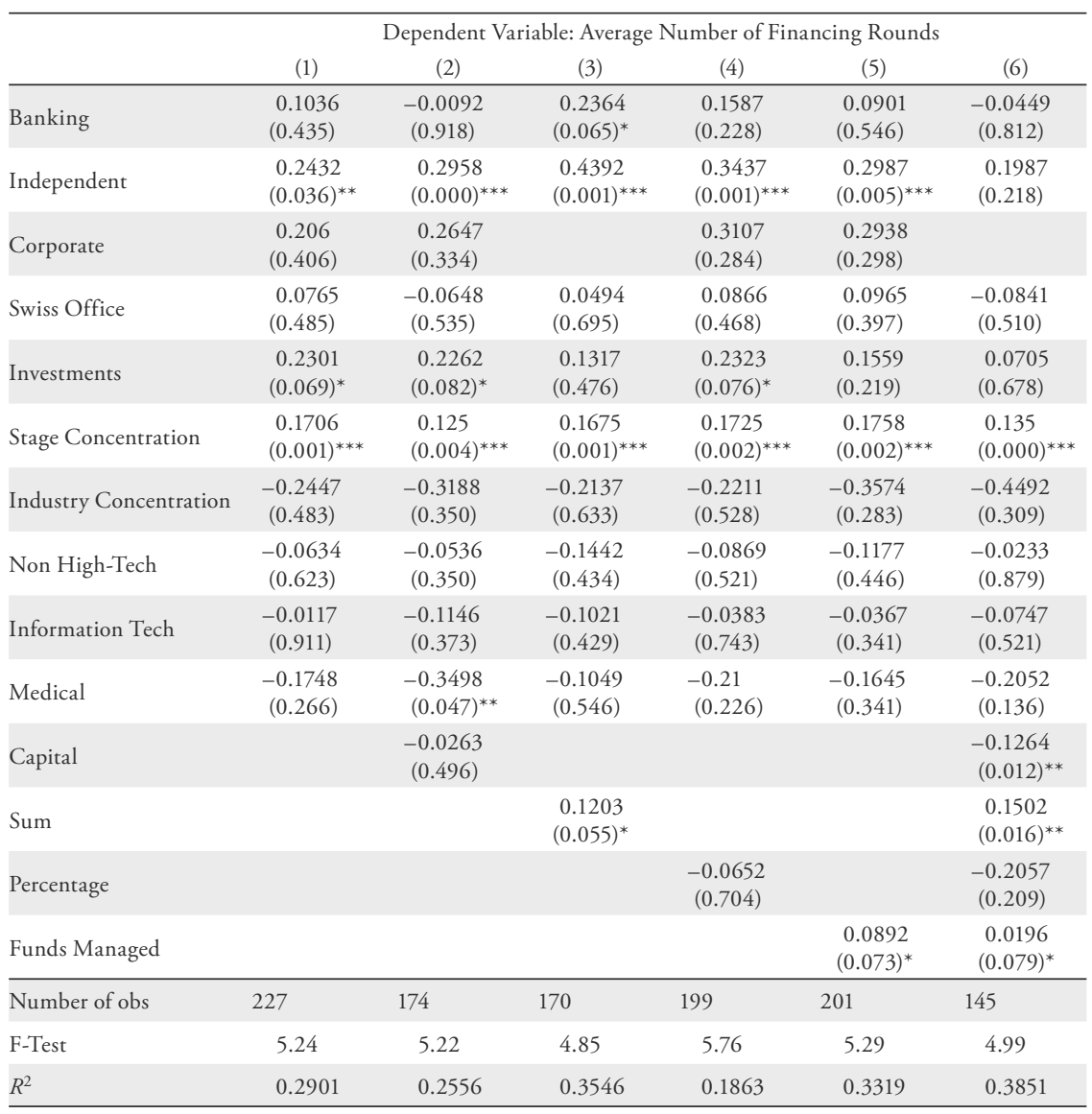

The table reports an OLS regression model using robust Standard Errors (Huber/White/sandwich) estimating the impact of Venture Capital provider characteristics on the average number of financing rounds in which capital is provided to the investment target. The sample for the first regression includes 227 Venture Capital providers that have made at least one investment in the period 1989-2005. For regression (2) I additionally included the Capital under Management for the VC firm. This variable enters the regression as the log. Moreover, I have included a dummy variable indicating the investment focus of the VC firm, i.e. whether the focus is on Non High-Tech, Information Technology, Medical and Life Sciences Products, or no specified focus at all. For regression (3) the sample has been reduced to $170 \mathrm{VC}$ firms. The variable Corporate has been dropped for this regression as not enough data points were available. Regression (3) uses the total Sum of investments made in Switzerland by the respective VC provider (enters the regression as the log), whereas regression (4) includes the investments made in Switzerland as a percentage of the overall sum of investments made. Regression (5) uses the number of Funds managed by the respective VCs as an additional explanatory variable. Regression (6) includes all variables simultaneously. The table reports the coefficient estimate along with the p-values in parentheses. Intercepts are not shown. The variables Public VC and "No Investment Focus" have been dropped to avoid perfect collinearity.

$*, * *, * * *$ denotes significance at the $10 \%, 5 \%$ or $1 \%$ level respectively. 
levels. Thus, banking and corporate investors do not differ in their use of staged capital infusions from public investors. With respect to the number of investments the data reveals that there is a positive and significant coefficient in three out of six regression specifications, albeit only at the $10 \%$ level. There seems to be some indication that experience (as measured by the number of deals) has a marginal positive impact on the observable staging behavior. However, the effect is not robust to alternative specifications used.

With respect to the use of stage financing TyKvova (2004) argues that local (in her case German) VCs usually invest in later stages and typically also carry out fewer investment rounds. This effect can, however, not be confirmed with the Swiss data. The coefficient associated with the dummy variable indicating whether a VC operates from a Swiss office is not found to be statistically significant in all six regressions indicating that VCs that have a closer proximity to the market do not differ in their use of stage financing from VCs that do not operate from a Swiss office.

Among the variables indicating the investment focus of the VCs one would expect that focusing firms are less prone to staging as a risk management device, as the knowledge and expertise acquired in the core markets render an extensive use of stage financing to overcome informational asymmetries obsolete. However, although the coefficients have a negative sign, which would be in line with this argumentation, none of the dummy variables is significant at conventional levels. Thus, there is no evidence that VCs focusing on specific industries differ in their use of staging mechanisms. In addition, the presence of industry knowledge that substitutes for staging is also not confirmed with respect to the industry concentration variable. Again, there is no significant evidence to confirm that firms that invest a larger portion of their investments in a specific industry are less inclined to stage the corresponding investments. One could expect that inexperienced VCs are not only likely to be more uncertain about the prospects of the venture, but might also be more unfamiliar with the particularities of the Swiss market itself. The coefficient associated with the variable "Percentage invested in Switzerland" is, however, not found to be significant indicating that VCs that invest more of their funds in Switzerland do not differ in their use of staging from less active VCs.

Nevertheless, with respect to the concentration of stages invested, one can infer that the coefficient associated with this variable is positive and significant (at the 1\% level) across all regression specifications. The results suggest that firms that focus on certain stages employ more financing rounds on average. In order to keep the entrepreneurs on a tighter leash staging mechanisms can be employed to reduce the downside exposure for the investments made. Moreover, staging reduces the cost associated with bad information (the real option value 
of abandonment) and decreases the agency costs of moral hazard. Accordingly, firms that concentrate their investments into specific rounds can mitigate risks more effectively when employing staging mechanisms.

In addition, I find that the overall sum invested in Switzerland has a positive coefficient (at the 10\% and 5\% level, respectively) indicating that firms with more funds invested in Switzerland are more likely to make use of staging. This indicates that more experienced VCs are more likely to make use of staging, supporting the results found in TYKVOVA (2004). This effect is strong with respect to the other size variable of the VCs, the number of funds managed, that also exhibits a positive and significant coefficient (at the 10\% level). The coefficient associated with the variable "Capital under Management" is only significant in one of the two regressions.

\subsection{The Decision to Join Forces among Providers of Venture Capital}

VC financing involves not only money for funding growth opportunities but also includes help in guiding managerial decisions. This characteristic is often referred to as "Smart Money". As some VCs lack resources and investment capabilities to deal with the difficulties and problems faced in VC financing it could therefore be beneficial to invest jointly with other partners. In order to test the impact of VC characteristics on the propensity to co-invest I estimate a tobit regression using the previously defined syndication ratio as the dependent variable. As the explanatory variables I use the dummy variables indicating the VC type (i.e. banking, independent etc.) along with the locality dummy that equals one when the VC operates from a Swiss office. Again, I use the focus variables of the VCs as explanatory variables. In addition, I use the average number of financing rounds employed for the VCs to test for interaction effects of staging and syndication activities. If the commitment to syndicate can mitigate the hold-up problem and align the interests of the VCs and the entrepreneur (as argued by FLUCK et al. (2005)), the firms that stage and monitor more extensively should also be more inclined to involve partners in the financing process. However, when firms join forces, where each firm contributes its share and might concentrate on specific rounds, it could well be that there are preferences among the VCs for certain stages or rounds. The extent to which firms collaborate could be influenced by the investment focus and the experience gained in certain stages. In order to control for specialization I include the two concentration measures for stages of development and industries into the analysis to see whether firms with a more pronounced focus on industries and stages might be less inclined to syndicate with a partner. The results are reported in table 4. 
Table 4: VC Characteristics and Syndication Activities

\begin{tabular}{|c|c|c|c|c|c|c|}
\hline & \multicolumn{6}{|c|}{ Dependent Variable: Syndication Ratio } \\
\hline & (1) & (2) & (3) & (4) & (5) & (6) \\
\hline Banking & $\begin{array}{c}-0.7735 \\
(0.583)\end{array}$ & $\begin{array}{c}-1.2236 \\
(0.406)\end{array}$ & $\begin{array}{c}-0.2833 \\
(0.753)\end{array}$ & $\begin{array}{c}-0.4757 \\
(0.719)\end{array}$ & $\begin{array}{c}-0.8289 \\
(0.549)\end{array}$ & $\begin{array}{c}-1.068 \\
(0.238)\end{array}$ \\
\hline Independent & $\begin{array}{c}-1.7976 \\
(0.182)\end{array}$ & $\begin{array}{c}-1.8772 \\
(0.192)\end{array}$ & $\begin{array}{r}-1.1555 \\
(0.136)\end{array}$ & $\begin{array}{c}-1.1388 \\
(0.361)\end{array}$ & $\begin{array}{c}-1.6081 \\
(0.221)\end{array}$ & $\begin{array}{l}-1.704 \\
(0.044)^{* *}\end{array}$ \\
\hline Corporate & $\begin{array}{c}-0.1747 \\
(0.915)\end{array}$ & $\begin{array}{c}0.2436 \\
(0.886)\end{array}$ & & $\begin{array}{c}0.836 \\
(0.610)\end{array}$ & $\begin{array}{c}0.6772 \\
(0.685)\end{array}$ & \\
\hline Swiss Office & $\begin{array}{c}-1.3185 \\
(0.053)^{*}\end{array}$ & $\begin{array}{c}-0.7967 \\
(0.180)\end{array}$ & $\begin{array}{l}-1.6677 \\
(0.003)^{* * *}\end{array}$ & $\begin{array}{l}-1.4429 \\
(0.047)^{* *}\end{array}$ & $\begin{array}{c}-1.1082 \\
(0.083)^{*}\end{array}$ & $\begin{array}{l}-1.4839 \\
(0.006)^{* * *}\end{array}$ \\
\hline Investments & $\begin{array}{c}-0.3426 \\
(0.683)\end{array}$ & $\begin{array}{c}-0.4844 \\
(0.478)\end{array}$ & $\begin{array}{c}-0.3301 \\
(0.613)\end{array}$ & $\begin{array}{c}-0.5001 \\
(0.512)\end{array}$ & $\begin{array}{c}-0.3605 \\
(0.650)\end{array}$ & $\begin{array}{c}-0.0994 \\
(0.861)\end{array}$ \\
\hline Stage Concentration & $\begin{array}{r}-0.1247 \\
(0.393)\end{array}$ & $\begin{array}{r}-0.1452 \\
(0.244)\end{array}$ & $\begin{array}{c}0.0473 \\
(0.740)\end{array}$ & $\begin{array}{r}-0.1167 \\
(0.377)\end{array}$ & $\begin{array}{c}-0.3605 \\
(0.429)\end{array}$ & $\begin{array}{c}0.0132 \\
(0.918)\end{array}$ \\
\hline Industry Concentration & $\begin{array}{r}1.1209 \\
(0.600)\end{array}$ & $\begin{array}{c}0.3061 \\
(0.860)\end{array}$ & $\begin{array}{c}0.331 \\
(0.845)\end{array}$ & $\begin{array}{r}0.2915 \\
(0.879)\end{array}$ & $\begin{array}{c}0.7838 \\
(0.702)\end{array}$ & $\begin{array}{r}0.6114 \\
(0.687)\end{array}$ \\
\hline Non High-Tech & $\begin{array}{l}-1.791 \\
(0.100)^{*}\end{array}$ & $\begin{array}{c}-1.4155 \\
(0.114)\end{array}$ & $\begin{array}{c}-2.0423 \\
(0.012)^{* *}\end{array}$ & $\begin{array}{c}-1.3415 \\
(0.170)\end{array}$ & $\begin{array}{c}-1.549 \\
(0.128)\end{array}$ & $\begin{array}{l}-1.833 \\
(0.011)^{* *}\end{array}$ \\
\hline Information Tech & $\begin{array}{c}-0.5447 \\
(0.371)\end{array}$ & $\begin{array}{c}-0.1988 \\
(0.709)\end{array}$ & $\begin{array}{r}-0.1021 \\
(0.429)\end{array}$ & $\begin{array}{r}-0.1911 \\
(0.740)\end{array}$ & $\begin{array}{c}-0.4202 \\
(0.477)\end{array}$ & $\begin{array}{c}0.1248 \\
(0.777)\end{array}$ \\
\hline Medical & $\begin{array}{r}1.1875 \\
(0.242)\end{array}$ & $\begin{array}{c}1.5993 \\
(0.090)^{*}\end{array}$ & $\begin{array}{c}1.1109 \\
(0.169)\end{array}$ & $\begin{array}{c}1.7761 \\
(0.084)^{*}\end{array}$ & $\begin{array}{c}1.4402 \\
(0.134)\end{array}$ & $\begin{array}{l}1.0923 \\
(0.139)\end{array}$ \\
\hline Average Rounds & $\begin{array}{c}1.2352 \\
(0.057)^{*}\end{array}$ & $\begin{array}{l}1.1196 \\
(0.047)^{* *}\end{array}$ & $\begin{array}{c}0.0737 \\
(0.855)\end{array}$ & $\begin{array}{c}1.1179 \\
(0.060)^{*}\end{array}$ & $\begin{array}{c}1.0662 \\
(0.072)^{*}\end{array}$ & $\begin{array}{r}0.3375 \\
(0.404)\end{array}$ \\
\hline Capital & & $\begin{array}{l}0.3803 \\
(0.008)^{* * *}\end{array}$ & & & & $\begin{array}{c}0.3165 \\
(0.029)^{* *}\end{array}$ \\
\hline Sum & & & $\begin{array}{c}0.2051 \\
(0.265)\end{array}$ & & & $\begin{array}{c}-0.0206 \\
(0.910)\end{array}$ \\
\hline Percentage & & & & $\begin{array}{c}0.4154 \\
(0.635)\end{array}$ & & $\begin{array}{c}0.9552 \\
(0.184)\end{array}$ \\
\hline Funds Managed & & & & & $\begin{array}{c}0.386 \\
(0.177) \\
\end{array}$ & $\begin{array}{c}-0.0201 \\
(0.516)\end{array}$ \\
\hline Number of obs & 227 & 174 & 170 & 199 & 201 & 145 \\
\hline$\chi^{2}$-Test & 25.06 & 30.8 & 40.45 & 24.69 & 26.84 & 43.47 \\
\hline Pseudo $R^{2}$ & 0.0278 & 0.1058 & 0.1694 & 0.0785 & 0.0835 & 0.2035 \\
\hline
\end{tabular}

The table reports a Tobit regression model estimating the impact of Venture Capital provider characteristics on the syndication ratio. The syndication ratio measures the number of joint investments as a percentage of the total number of transactions undertaken. The sample for the first regression includes 227 Venture Capital providers that have made at least one investment in the period 1989-2005. Additionally, the regressions include information on the average number of round financing used for the investments made, a Herfindahl measure of concentration for the industries invested in as well as for the concentration on stages (i.e. Start Up/Seed, Early Stage and Late Stage). For regression (2) I additionally included the Capital under Management for the VC firm which enters the regression as the log. Moreover, I have included a dummy variable indicating the investment focus of the VC firm, i.e. whether the focus is on Non High-Tech, Information Technology, Medical and Life Sciences Products, or no specified focus at all. For regression (3) the sample has been reduced to $170 \mathrm{VC}$ firms. The variable Corporate has been dropped for this regression as not enough data points were available. Regression (3) uses the total Sum of investments made in Switzerland by the respective $\mathrm{VC}$ provider (enters the regression as the log), whereas regression (4) includes the investments made in Switzerland as a percentage of the overall sum of investments made. Regression (5) uses the number of Funds managed by the respective VCs as an additional explanatory variable. Regression (6) includes all variables simultaneously. The table reports the coefficient estimate along with the p-values in parentheses. Intercepts are not shown. The variables Public VC and "No Investment Focus" have been dropped to avoid perfect collinearity.

${ }^{*},{ }^{* *},{ }^{* *}$ denotes significance at the $10 \%, 5 \%$ or $1 \%$ level respectively. 
Bernile et al. (2005) point out that the variations in VC quality might be attributable to the quality of general and limited partners as well as to the affiliation of the fund (corporate/government). Table 4, however, indicates that among the $\mathrm{VC}$ affiliation dummies none of the coefficients is significant at conventional levels. This suggests that $\mathrm{VC}$ affiliation itself does not impact the decision to syndicate with a partner solely. The coefficient associated with the locality dummy is negative and significant in five out of six regression specifications (at varying levels of confidence). This indicates that foreign VC investors make more extensive use of syndication efforts when investing in the Swiss market. Concerning the need to syndicate for foreign investors GoMPERs (1995) points out that entrepreneurial firms that are more disperse require more effort to monitor in order to mitigate information asymmetries. The size of a portfolio for VCs investing across borders is likely to be smaller as the value added effect is diluted by the more intense monitoring activities. Syndication allows the foreign investors to spread their capital over a larger number of deals without diluting effort available to the other funded firms. More importantly, syndication can serve as an entrance strategy to new markets in order to generate sufficient deal flow. Amortizing the locality advantages of closely situated Swiss VCs and participating in their specific market knowledge might be an even more important reason. Most likely, foreign VCs generate a portfolio effect by investing smaller amounts of money into a larger number of companies and benefit through the pre-selection of other involved VCs.

With respect to the need to syndicate from a resource point of view one could argue that syndication becomes more important for the VCs when investing outside the predominant investment activities in order to get access to deal flow and to reduce the level of asymmetric information in the VC - Entrepreneur relationship due to unfamiliarity with the local market. Therefore, one would expect that VCs investing outside the scope of their normal investment activities need to rely more extensively on syndication. Nevertheless, the coefficients associated with the "Percentage invested in Switzerland" and the "Sum invested in Switzerland" are not found to be significant. Firms that are more acquainted with the local particularities do not differ in syndication effort from inexperienced counterparts. The effect can also not be confirmed by the two concentration measures. Here one could expect to see firms that are more familiar with certain stages or that acquired expertise within a certain industry relying less on syndication. I do find that neither the coefficient for the stage concentration nor the coefficient associated with the industry concentration is significant. Firms that concentrate their investments do not differ in their reliance on syndication efforts. 
However, I find that the coefficient associated with the variable "Capital under Management" is positive and significant (at the 1\% and 5\% level, respectively). For larger VCs the lower incentive to syndicate from a resource driven perspective seems to be outweighed by the potential to benefit from a more central network position within the VC community. HochBerg et al. (2006) argue that the influence a $\mathrm{VC}$ derives from having many syndication partners is useful even if the VC does not syndicate a specific investment. Thus, investment targets benefit from being backed by a VC that has many ties within the industry and over other well-connected investors. Building up a reputation via a track record of deals enables the VCs to occupy a central position within the VC community. Moreover, better-networked VCs are also the older and more experienced VCs that add more value to the investment targets. ${ }^{1}$

With respect to the average number of rounds included I find that the coefficient is positive and significant in four out of six regression specifications. This suggests evidence for the argumentation of FLUCK et al. (2005) that firms which realize the benefit of staging might on the same turn realize the value added in financing start ups through the involvement of partners. In order to create complementarities in managing and advising the funded firms as well as by combining financial resources firms therefore join forces with partners. In addition to this, FLUCK et al. (2005) point out that the commitment to syndicate can protect the entrepreneur from dilution and thus mitigates the problem of hold-up. Consequently, VCs that make use of staging are also more open to syndication.

1 The empirical method chosen in this paper analyzes syndication from the side of the VCs solely. In order to test whether syndication is associated with a higher financing need for the funded firm I estimated a regression including industries dummies as well as the size of the funded firm (measured by the log of sales and employees). Despite the industry dummy for Biotech, Electronics and Software none of the other variables turns out to be significant. It is, however, still possible that there is endogenous matching, i.e. larger VCs choose fims with a higher financing need, so that the effects across VCs wash out. The classical way to circumvent the endogeneity problem, would be to make use of an instrumental variable that would be independent of the outcome (syndication) but related to VC characteristics (such as experience or capital under management) in order to account for the VCs choosing the funded firms. However, the complexity of the underlying decisions makes it difficult to find a suitable instrument. SORENSEN (2006) for example suggests the use of a two-sided matching model in order to overcome the problem of finding a suitable instrument. However, the computational tractability of the structural equations only allow for an analysis of initial investments rather then subsequent rounds (with a higher financing need). In order to mitigate potential problems I have included various variables in my analyses that should alleviate a potential bias. 


\subsection{Monitoring, Syndication and the Impact on Successful Venturing Activities}

Recent studies stress the importance of financing mechanisms for carrying out an investment deal successfully and also point out the value enhancing effect of syndication activities. LERNER (1994) documents a positive effect of joint decision making on mitigating agency conflicts between the $\mathrm{VC}$ and the entrepreneur. The evaluation of the venture proposal by different $\mathrm{VC}$ companies operating in a syndicate reduces adverse selection. Consequently, the decision making process becomes more efficient and leads to better results if the project is only undertaken when approved by two or more parties. Hence, one would expect to see a positive effect of syndication efforts on company performance as argued in BRANDER et al. (2002) and documented in Audretsch and Lehmann (2004).

With respect to the effect of staging on company performance FLUCK et al. (2005) argue that the commitment to syndicate assures a higher effort of the entrepreneur and yields more favorable financing terms in return. In addition, they put forward the argumentation that syndication gives better incentives to the entrepreneur and consequently increases the value of the venture. Moreover, Davila et al. (2003) emphasize the different roles of VC staging. First round investments are intended to provide capital to a cash constraint entrepreneur while late stage financing is intended to overcome information asymmetries and to mitigate the agency conflicts present in the relationship between the $\mathrm{VC}$ and the entrepreneur. The early stage investment is therefore characterized by uncertainty over the future outcome and VCs can limit their downside exposure by not committing all capital upfront and keeping their option to abandon alive. Once the portfolio firm makes progress in developing products and management structures, the $\mathrm{VC}$ can permanently update its information and can commit further capital to promote growth.

In this sense one would expect to see a value enhancing effect of staging and syndication efforts alike for the portfolio companies. In order to test for the relationship between the extent of staging and syndication and the chances of investment success I estimate a tobit regression with the success rate of the VCs as the dependent variable. Similar to Hochberg et al. (2005) the success rate measures the percentage of deals that have been successfully exited. Here I take the percentage of investment targets that have been successfully sold via a trade-sale, an acquisition or exited via an IPO to the total number of deals undertaken. As the explanatory variables I use the category dummies, the focus of the VCs, the locality dummy (Swiss Office), the measures of stage and industry concentration and the variables describing the Capital under Management, the total Sum invested in Switzerland, the percentage of the portfolio invested in Switzerland 
and the total number of funds that have been managed by the corresponding VC. Table 5 reports the results.

Again, one can infer that none of the $\mathrm{VC}$ affiliation dummies is significant indicating that affiliation itself has no impact on the chances of success for a positive exit. Neither the stage concentration nor the industry concentration variable exhibit a significant effect on the success rate. VCs that are investing more in certain stages do not improve their chances of successful exits in comparison to firms investing more broadly. Moreover, no effect can be found for firms focusing on specific industry segments. None of the focus dummies is significant at conventional levels. With respect to the variables indicating the size of the VC I find that neither the number of investments undertaken, nor the capital under management or the sum invested in Switzerland have an effect on the success rate of VCs. The variable "Funds managed" is positive and marginally significant in one out of two regression specifications, indicating that firms that have managed more funds on average over the past have higher chances of successfully exiting their investments made.

Interestingly, the coefficient associated with the locality dummy "Swiss Office" is negative and significant. Swiss VCs therefore seem to have problems either in exiting their deals, or might even exhibit difficulties in providing the necessary value added in managing their investments. However, interpretations have to be made with a note of caution, as the variable is only significant in two out of six regression specifications. Nonetheless, this effect is supported by the negative and significant coefficient (at the 5\% level in regression specification four, but not in six) associated with the variable "Percentage invested in Switzerland". Therefore it might be worthwhile to further investigate the issue raised here in order to shed light on the potential causes and consequences of the lower success rates of more locally embedded VCs. Seemingly, we can infer that VCs that are more active in the Swiss market are less successful in exiting their deals. Alternatively, one could argue that the higher level of experience in investing for foreign VCs coming from more established VC environments leads them to better select deals and manage them accordingly.

The results presented in table 5 show that syndication has a positive and significant effect (across all regression specifications) on the success rate of VCs. Here I find evidence on a value added effect of VC Syndication. This could on the one hand speak for Lerner's Selection Hypothesis at the pre-investment stage and alternatively for the claim of BRANDER et al. (2002) that syndication provides a benefit in terms of value adding at the post-investment stage. LeRner (1994) suggests that the evaluation of the same venture proposal by different VC companies operating in a syndicate reduces the potential danger of adverse selection. 
Table 5: VC Syndication, Staging Activities and Investment Success

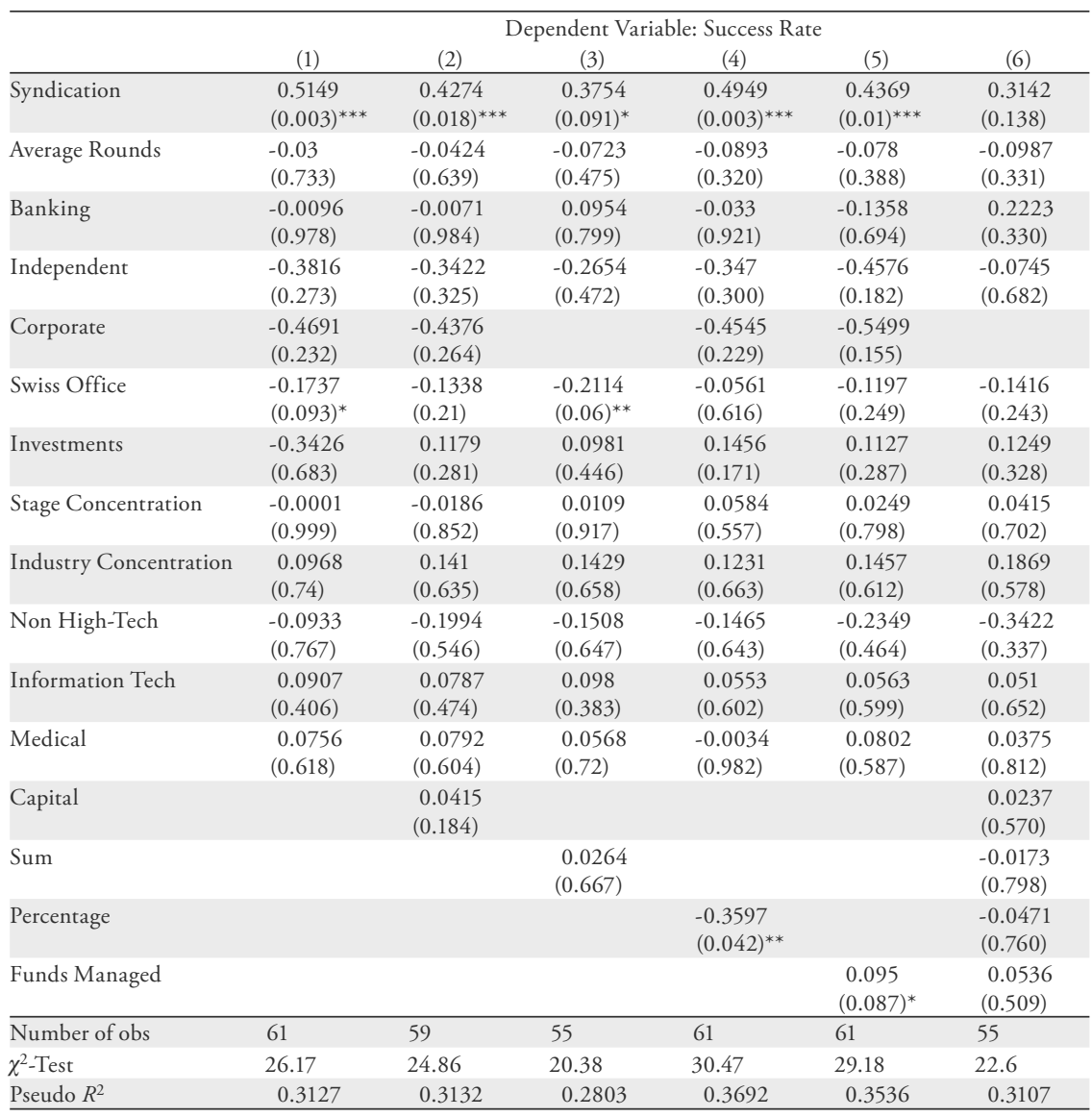

The table reports a Tobit regression model estimating the impact of Venture Capital provider characteristics on the Success Rate of the VC firms. The Success Rate is measured as the percentage of investments that have been successfully exited through a trade-sale, an acquisition by another party or via an IPO. The sample for the first regression includes 227 Venture Capital providers that have made at least two investment in the period 1989-2005. Additionally, the regressions include information on the average number of round financing used for the investments made, a Herfindahl measure of concentration for the industries invested in as well as for the concentration on stages (i.e. Start Up/Seed, Early Stage and Late Stage). Moreover, I have included the Syndication Ratio for each VC and the Average Number of Financing Rounds in order to estimate the effects joint investment effort and sophisticated Financing arrangements used. For regression (2) I additionally included the Capital under Management for the VC firm which enters the regression as the log. Moreover, I have included a dummy variable indicating the investment focus of the VC firm, i.e. whether the focus is on Non High-Tech, Information Technology, Medical and Life Sciences Products, or no specified focus at all. For regression (3) the sample has been reduced to $55 \mathrm{VC}$ firms. The variable Corporate has been dropped for this regression as not enough data points were available. Regression (3) uses the total Sum of investments made in Switzerland by the respective VC provider (enters the regression as the log), whereas regression (4) includes the investments made in Switzerland as a percentage of the overall sum of investments made. Regression (5) uses the number of Funds managed by the respective VCs as an additional explanatory variable. $(\rightarrow$ 
The combined effort to assess the quality of a venture helps VC investors to overcome informational asymmetries as the entrepreneurs typically know more about the investment opportunity they seek funding for and might overstate the attractiveness of his business proposal (SORENSEN and STUART, 1999). BRANDER et al. (2002) argue with a value added stemming from the involvement of other VC partners and the complementarity of skills. An investor acts according to the Value Added Hypothesis when he believes that the involvement of other venture capitalists would add some value to the venture. The benefit of involving co-investors is derived from heterogeneous skills and information different VCs can contribute to the management of the funded firm.

The previous results from the syndication analysis showed that local firms do rely to a lesser extent on syndication. In addition, I find that the success rates of Swiss VCs tend to be lower than for comparable foreign investors. Here it might be interesting to further investigate why Swiss firms refrain from joining forces with partners. Likely, the relatively inexperienced firms do not realize the value adding stemming from joint investment activity. Bearing in mind that the Swiss market is, by and large, characterized by a much lower number of deals as compared to other continental VC markets the lack of experience by local market participants might have an influence on the observable financing and syndication behavior.

\section{Concluding Remarks}

In this paper I analyse the market for Venture Capital in Switzerland along several dimensions. With respect to the use of staging mechanisms I investigate to which extent it is used in venture financing to reduce investment risks and to overcome information asymmetries. I find that among the different affiliations of VC investors in Switzerland especially independent investors make more extensive use of stage financing. Moreover, firms that focus more extensively on certain stages employ on average more financing rounds. In order to keep the entrepreneurs on a tighter leash staging mechanisms can be employed to reduce the downside exposure for the investments made. In addition, I find that firms with more funds invested in Switzerland are more likely to make use of staging.

\footnotetext{
Regression (6) includes all variables simultaneously. The table reports the coefficient estimate along with the p-values in parentheses. Intercepts are not shown. The variables Public VC and "No Investment Focus" have been dropped to avoid perfect collinearity.

, ${ }^{* *},{ }^{* * *}$ denotes significance at the $10 \%, 5 \%$ or $1 \%$ level respectively.
} 
This effect is strong with respect to the other size variables of the VCs included. With respect to the use of syndication as a mechanism to lever upon capabilities of other partners in the selection and management of investments I find that foreign investors make more use of syndication efforts when investing in the Swiss market. Syndication allows the foreign investors to spread their capital over a larger number of deals without diluting effort available to the other funded firms Moreover, syndication can serve as an entrance strategy to new markets

In addition, I find evidence that firms, which realize the benefit of staging, do also become conscious of the value added in financing start ups by involving partners. In order to create complementarities in managing and advising the funded firms as well as to combine financial resources, VCs join forces with partners. Concerning the value added effect of Syndication and Staging Activities I find that Swiss VCs seem to have problems either in exiting their deals, or might even exhibit difficulties in providing the necessary value added in managing their investments. Overall I show that VCs that are more locally embedded (as measured by the Swiss office dummy) do exhibit lower success rates for their investment portfolio. The outcomes are surprising to the extent that one would expect that VCs that are located closer to their portfolio companies have a competitive advantage in comparison to their foreign competitors. Moreover, I show that syndication positively impacts the success rates of VCs finding evidence on a value added effect of $\mathrm{VC}$ syndication. However, to make clearer distinctions between the origin of a $\mathrm{VC}$ and the likelihood of success an analysis in the style of Maula and Murray (2000) using "hard" data such as IPO valuations or investment outcomes would be necessary to possibly quantify the added value through syndication. In general the relationship between syndication and firm value of the funded firm is far from being clarified.

The lack of additional comprehensive studies on the syndication behaviour of European VCs calls for further research in this field. As MANigarT et al. (2002) point out; there is a range of economic, legal, institutional and cultural differences influencing the environment in which VC organisations operate. Thus, the miscellaneous and comprehensive conclusions drawn on the North American VC market are not necessarily applicable to the European VC industry. Additional comparisons on the syndication practices in Europe, the US and Asia are needed and an interesting avenue for future research. Further studies are also needed to reveal if the European VC industry is becoming more uniform and standardised and to what degree trans-national syndicates have helped to establish common norms and working methods. 


\section{References}

Audretsch, D. und E. Lehmann (2004), "Debt or Equity: The Role of Venture Capital in Financing High-Tech Firms in Germany", Schmalenbach Business Review, Vol.56, No.4, pp.340-357.

Bernile, G., D. Cumming and E. Lyandres (2005), "The Size of Venture Capitalists' Portfolios", Working Paper No. FR 03-17, Simon Business School.

Bienz, C. and J. Hirsch (2005), "The Dynamics of Venture Capital Contracts", Working Paper, Center for Financial Studies, Frankfurt.

Brander, J. A., W. Antweiler and R. Amit (2002), "Venture Capital Syndication: Improved Venture Selection versus the Value-Added Hypothesis", Journal of Economics and Management Strategy, Vol. 11, No. 3. pp.423-452.

Bygrave, W. D. (1987), "Syndicated Investments by Venture Capital Firms: A Networking Perspective”, Journal of Business Venturing, Vol.2, No. 1, pp. 139-154.

Davila, A., G. Foster and M. Gupta (2003), "Staging Venture Capital: Empirical Evidence on the Differential Role of Early versus Late Rounds", Working Paper, Stanford University, Stanford.

Fluck, Z., K. Garrison and S. Myers (2005), "Venture Capital Contracting and Syndication: An Experiment in Computational Corporate Finance", NBER Working Paper No. 11624, Boston.

Gompers, P. (1995), "Optimal Investment, Monitoring, and Staging of Venture Capital”, Journal of Finance, Vol. 50, No. 5, pp. 1461-1489.

Hochberg, Y., A. LjungQvist and Y. Lu (2005), "Whom You know Matters: Venture Capital Networks and Investment Performance.", Journal of Finance, forthcoming.

Hopp, C. and F. Rieder (2006), "What Drives Venture Capital Syndication?”, Working Paper, University of Konstanz.

Jeng, L. and P. Wells (2000), "The Determinants of Venture Capital Funding: Evidence Across Countries", Journal of Corporate Finance, Vol. 6, No.3, pp. 241-289.

Lerner, J. (1994), "The Syndication of Venture Capital Investments", Financial Management, Vol.23, No.3, pp. 16-27.

Manigart, S., H. Bruining, P. Desbrieres, H. Landstroem, A. Lockett, M. Meuleman, U. Hommel and M. Wright (2005), "The Syndication Decision of Venture Capital Investments.", Entrepreneurship: Theory \& Practice, forthcoming. 
Manigart, S., K. De Waele, M. Wright, K. Robbie et al. (2002), "Determinants of Required Return in Venture Capital Investments: A Five-Country Study", Journal of Business Venturing, Vol. 17, No.4, pp. 291-312.

Maula, M. and G. Murray (2000), "Corporate Venture Capital and the Creation of US Public Companies: The Impact of Sources of Venture Capital on the Performance of Portfolio Companies", Working Paper, Helsinki University of Technology and London Business School.

Sahlman, W. A. (1990), "The Structure and Governance of Venture Capital Organizations", Journal of Financial Economics, Vol. 27, No. 4, pp. 473-521.

Sorenson, O. and T. Stuart (1999), "Syndication Networks And The Spatial Distribution of Venture Capital Investments", Working Paper, University of California and University of Chicago.

Sorensen, M. (2006), "How Smart is Smart Money? A Two-Sided Matching Model of Venture Capital", Journal of Finance, forthcoming

Talmor, Eli and Charles J. Cuny (2005), “The Staging of Venture Capital Financing: Milestone vs. Rounds", EFA 2005 Moscow Meeting Paper.

Tykvova, T. (2004), "Who Are the True Venture Capitalists in Germany?", ZEW Discussion Paper No. 04-16, Mannheim.

WANG, S. and H. Zhou (2002), "Staged Financing in Venture Capital: Moral Hazard and Risks", Journal of Corporate Finance, Vol. 10, No. 1, pp. 131-155. 